\title{
Influence Of Tool Geometry And Performance Characteristics of En-19 Steel By Edm Using Taguchi Method
}

\author{
Buschaiah.K ${ }^{1}$,Parshuramulu. $\mathrm{A}^{2}$,Laxminarayana.P $\mathrm{P}^{3}$ \\ ${ }^{I}$ (Dept of Mech. Engg.,College of Engg.,Osmania University Hyderabad,Telangana State, India)
}

\begin{abstract}
The objective of the present work is to optimize the process parameters in EDM by using Taguchi's design of experiments, which extensively been used. The process parameters chosen for the experiment are discharge current, open voltage, Toff, Ton and tool geometry. These parameters were selected because they can potentially affect Electrode wear ratio, material removal rate and tool wear rate in EDM operation and considered to be controllable factors. Since the EWR, MRR and TWR determine the economics of machining and rate of production, it is important to optimize the process parameters suitably to maximize the MRR and minimize the EWR.
\end{abstract}

Keywords: EDM, MRR, TWR, Electrodes

\section{Introduction}

In the present study the most common and easily available electrode materials like copper were taken under consideration during machining of EN19Steel. Wear of the electrode along the direction of movement of the electrode can be compensated by imparting additional movement of the electrode. But the Wear along the cross-section of the electrode cannot be compensated. This phenomenon results in inaccuracy in the dimension of the cavities made by die-sinking technique. In the present study an analysis has been done to evaluate the EW along the cross-section of the electrode compared to the same along its movement. An analysis has also been done on the comparative performance of copper electrode material.

Electrical discharge machining (EDM) process is based on thermal energy, which comes through innumerable sparks between the tool electrode and the work piece. Electrical discharge machining (EDM) processes are now gaining in popularity, since many complex 3D shapes can be machined using a simple shaped tool electrode. The pair of electrodes are sunken into a dielectric fluid and open voltage is applied. During the process, both parts are placed very close one from the other (gap distance is in the order of $\mu \mathrm{m}$ ), to permit plasma channel creation between the anode and the cathode. When gap width between the tool and the electrode achieves the maximum sparking gap width, a micro-conductive ionized path appears and the electric spark occurs achieving temperatures up to 15.000 or $20.000{ }^{\circ} \mathrm{C}$ Conductive material is then molten and/or vaporized from the work piece. The absence of direct contact between the tool and the electrode caused by the nature of the process avoid common process problems such as mechanical stresses and vibrations caused by conventional machining processes Although EDM is mainly used in electrically conductive work materials, the usage of certain additives (such as titanium carbide (Tic), titanium boride (TiB2) or zirconium boride ( $\mathrm{ZrB} 2$ ), among others) permits initially non-conductive materials to be machined by EDM process. Collateral effects like the diminution of mechanical resistance are then compensated with other additives.

\section{Experimental methodology}

The work material chosen for this experimental work is EN19 (Emergency number) Steel. It was cut into 21 specimens cutting by power hacksaw and then machined using surface grinding machine to the size of $\mathrm{mm}$ a block of $45 \mathrm{~mm} \times 5 \mathrm{~mm}$ various chemical composition of EN19 Steel was shown in Table 1

Table 1 Chemical composition of EN19 steel

\begin{tabular}{|l|l|l|l|l|l|}
\hline Element & $\mathrm{C} \%$ & $\mathrm{Si} \%$ & $\mathrm{Mn} \%$ & $\mathrm{Cr} \%$ & $\mathrm{Mo} \%$ \\
\hline Composition (\%) & $0.37-0.4 \%$ & $0.25 \%$ & $\begin{array}{l}0.70- \\
0.77 \%\end{array}$ & $0.98-1.20 \%$ & $0.21-0.30 \%$ \\
\hline
\end{tabular}

\subsection{Electrode material}

The properties of electrode materials are presented in the tables below historically, copper was the first material used in EDM machine. Electrolytic copper is preferred. Electrolytic copper consists of copper 99.8\% the main advantage of copper is the very good surface finish it produces as well as relatively stable electrical process. The disadvantage, the electrode wear is very high with relatively small material removal. It is 
acceptable for small work pieces (50 to 100 in 3 ) where a good surface finish is required and the flushing is delicate (high risk instability)

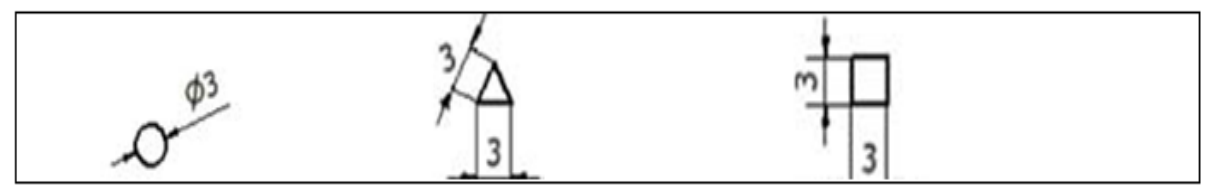

Fig 1 Different Shapes of Tool Geometry Copper Electrodes

1.2.

\subsection{Experimental procedure:}

After cutting a block of work piece of circular section $45 \mathrm{~mm} \times 5 \mathrm{~mm}$ the specimen is fixed with the help of T-bolts in the same way electrode is also fitted into the tool holder. This tool holder is already fitted to the work header with collets. After this setup dielectric fluid is pumped into a tank up to $40 \mathrm{~mm}$ above the specimen and then spark is on at pre-defined setting after each experiment the weights of specimen and electrode are measured with digital weighing machine

In this 18experiments time is independent and depth should be maintained at $1 \mathrm{~mm}$ constant. First experiment was conducted by maintaining the peak current at $6 \mathrm{amp}$, and voltage at $8 \mathrm{~V}$ and pulse on time $50 \mu \mathrm{s}$, pulse off time $15 \mu \mathrm{s}$ the experiment was repeated all the other experiment trails were conducted as per the orthogonal array table 2. and final results of The corresponding MRR, TWR and WR values were measured and are tabulated in table 3 .

Table 2. Process parameters and there levels

\begin{tabular}{|l|l|l|l|l|}
\hline S.NO & PARAMETERS & Level 1 & Level 2 & Level 3 \\
\hline 1 & A. Voltage(V) & 8 & 9 & - \\
\hline 2 & B. Current(I) & 6 & 8 & 10 \\
\hline 3 & C Pulse on time $(\mu \mathrm{s})$ & 50 & 100 & 150 \\
\hline 4 & D. Pulse off time $(\mu \mathrm{s})$ & 13 & 25 & 50 \\
\hline 5 & E . Geometry Shapes & G1( $(\mathrm{)})$ & G2( $(\Delta)$ & G3(O) \\
\hline
\end{tabular}

\section{Evaluation of performance characteristics}

The performance characteristics i.e Metal Removal Rate (MRR), Tool Wear Rate (TWR) and Wear Ratio (WR).are measured as follows

Testing and Evolution of Material Removal Rate (MRR) in mm3/min

This is a rate of work piece material removal per unit time.

$\operatorname{MRR}(\mathrm{mm} 3 / \mathrm{min})=[1000 *$ weight loss $(\mathrm{gm}) /.[$ density $(\mathrm{gm} . / \mathrm{cc}) *$ machining time $(\mathrm{min})]$

Testing and Evolution of Tool wear Rate (TWR) (mm3/min)

This is a rate of Electrode or Tool wear per unit time

It is similar to MRR EWR (or) TWR= [1000*Electrode weight loss (gm)] [density (gm./cc)*machining time (min)]

\section{Electrode Wear Ratio (\%)}

It is defined as the ratios of volumetric Electrode wear and work piece material removal measured in (\%).

Electrode wear $(\%)=[$ Volumetric Electrode wear $(\mathrm{mm} 3 / \mathrm{min}) * 100] /[\mathrm{MRR}(\mathrm{mm} 3 / \mathrm{min})]$

Density of EN-19 steel $=7.5 \mathrm{gm} / \mathrm{cm} 3$, Density of copper electrode $=8.92 \mathrm{grm} / \mathrm{cm} 3$

\section{Weighing machine:}

Precision balance was used to measure the weight loss of the work piece and tool material before and after machining .This machine capacity is 200 gram and accuracy is 0.0001 gram 


\begin{tabular}{|l|c|c|c|c|c|}
\multicolumn{7}{l}{ Matrix Observation Table } \\
\hline S.NO & $\begin{array}{l}\text { Voltage } \\
(\text { V) }\end{array}$ & $\begin{array}{l}\text { Current } \\
(\mathrm{I})\end{array}$ & Ton $(\mu \mathrm{s})$ & Toff( $\mu \mathrm{s})$ & Geometry \\
\hline 1 & 8 & 6 & 50 & 13 & $\square$ \\
\hline 2 & 8 & 6 & 100 & 25 & $\Delta$ \\
\hline 3 & 8 & 6 & 150 & 50 & O \\
\hline 4 & 8 & 8 & 50 & 13 & $\Delta$ \\
\hline 5 & 8 & 8 & 100 & 25 & O \\
\hline 6 & 8 & 8 & 150 & 50 & $\square$ \\
\hline 7 & 8 & 10 & 50 & 25 & $\square$ \\
\hline 8 & 8 & 10 & 100 & 50 & $\Delta$ \\
\hline 9 & 8 & 10 & 150 & 13 & O \\
\hline 10 & 9 & 6 & 50 & 50 & O \\
\hline 11 & 9 & 6 & 100 & 13 & $\square$ \\
\hline 12 & 9 & 6 & 150 & 25 & $\Delta$ \\
\hline 13 & 9 & 8 & 50 & 25 & O \\
\hline 14 & 9 & 8 & 100 & 50 & $\square$ \\
\hline 15 & 9 & 8 & 150 & 13 & $\Delta$ \\
\hline 16 & 9 & 10 & 50 & 50 & $\Delta$ \\
\hline 17 & 9 & 10 & 100 & 13 & $\mathrm{O}$ \\
\hline 18 & 9 & 10 & 150 & 25 & $\square$ \\
\hline
\end{tabular}

Table 4.Effect of Input parameters on MRR, TWR, and WR

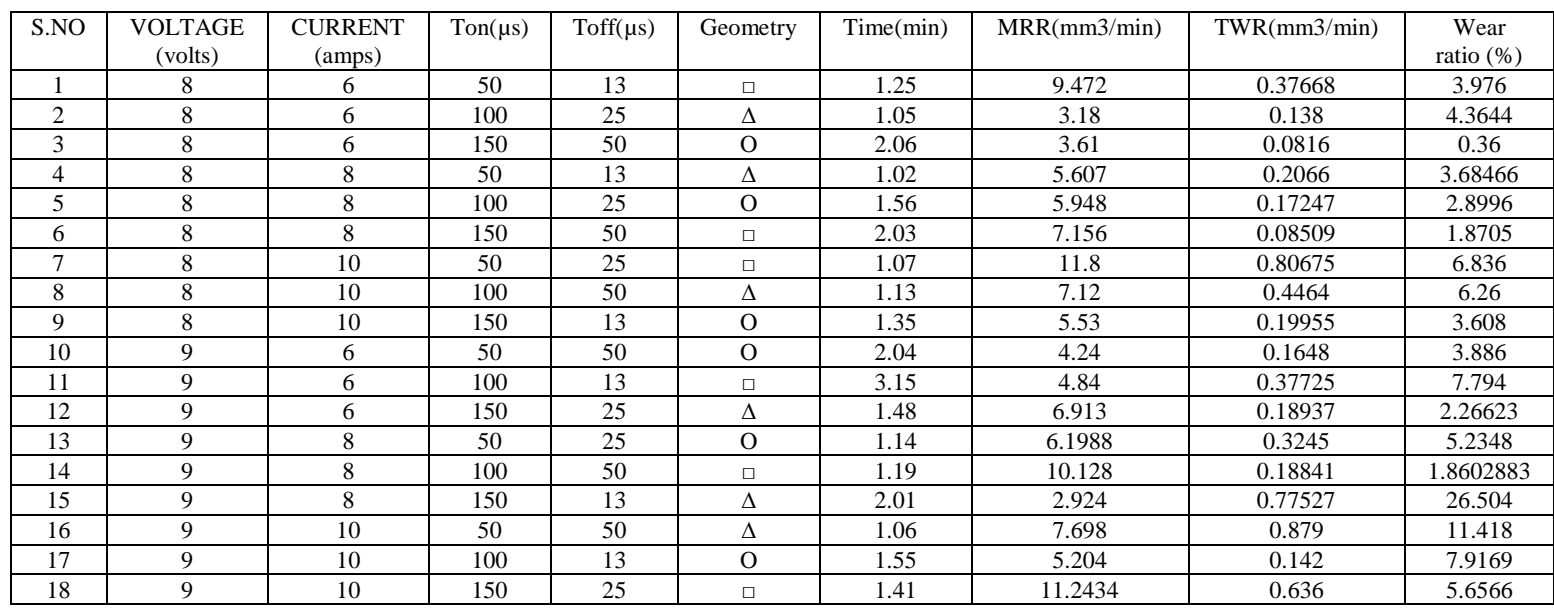

\section{Results \& Discussions}

\section{Review main effect and interaction plots}

In the analysis using average of trial results, all calculations involved in the analysis is performed using the column of average of trial results values the main effect i.e. the effects of process parameters on the response characteristic when the process parameters change from one level to another are given figs6.1 and 6.2.the last column of the above fig is difference between the average of level 2 and level 1.for example, the average results of metal removal rate of the 18 samples with the factor pulse off time set to level 1 is 5.973 , and that to level 2 is 7.546 so there difference L2-L1 is 1.573 the difference gives some indication of the relative influence of the factors to the variation of results more rigorous measures of the influence of each factors to the variation of results more rigorous measures of the influence of each factor will be decided by the F-Factor and confidence level shown in the analysis of variance (ANOVA) .it should be noted that all of the data generated will not be shown.

For example only L2-L1 is shown here there similarly data for level 3minus level1 level3 minus level 2.these are not shown as information here because that they are already encoded in to the data presented. 


\subsection{Effects of control factors on Metal Removal Rate (MRR)}

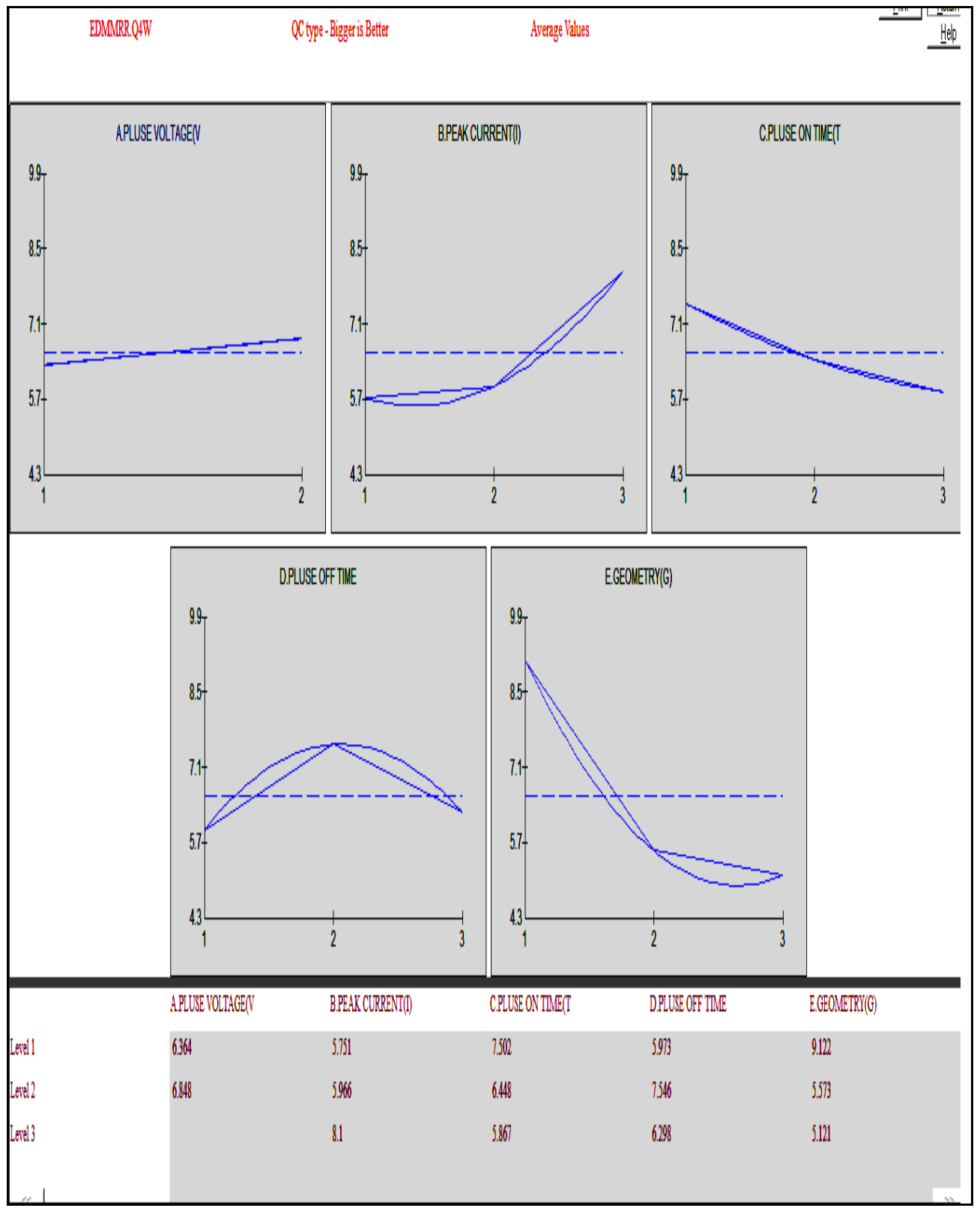

Fig 2. Effects of control factors on Metal Removal Rate

Fig 2.Graphically illustrates the effect of each level of five of the factors on the measured response in each plot $\mathrm{x}$-axis refers to the level, and $\mathrm{y}$-axis refer to the measured metal removal rate in $\mathrm{mm} 3 / \mathrm{min}$ in this peak current, tool geometry is the most significant factors influencing for metal removal rate . The peak current (I) is directly proportional to MRR in the range of 6 to 10A. This is expected because an increase in pulse current produces strong spark, which produces the higher temperature, causing more material to melt and erode from the work piece. Besides, it is clearly evident that the other factor does not influence much as compared to current but, with increase in peak current from 6A to 10A MRR increases slightly However, MRR decreases monotonically with the increase in pulse on time.

MRR usually increases with Ton up to a maximum value after which that it starts to decrease. This is due to the fact that with higher Ton, the plasma formed between the Inter electrode gap actually hinders the energy transfer and thus reduces MRR. In this experiment the value of pulse durations are 50, 100 and $150 \mu \mathrm{s}$ which miss the peak values. So, the plotted graph of pulse duration (Ton) vs MRR, as show decreasing trends only 


\subsection{Effects of control factors on Tool wear rate (TWR)}

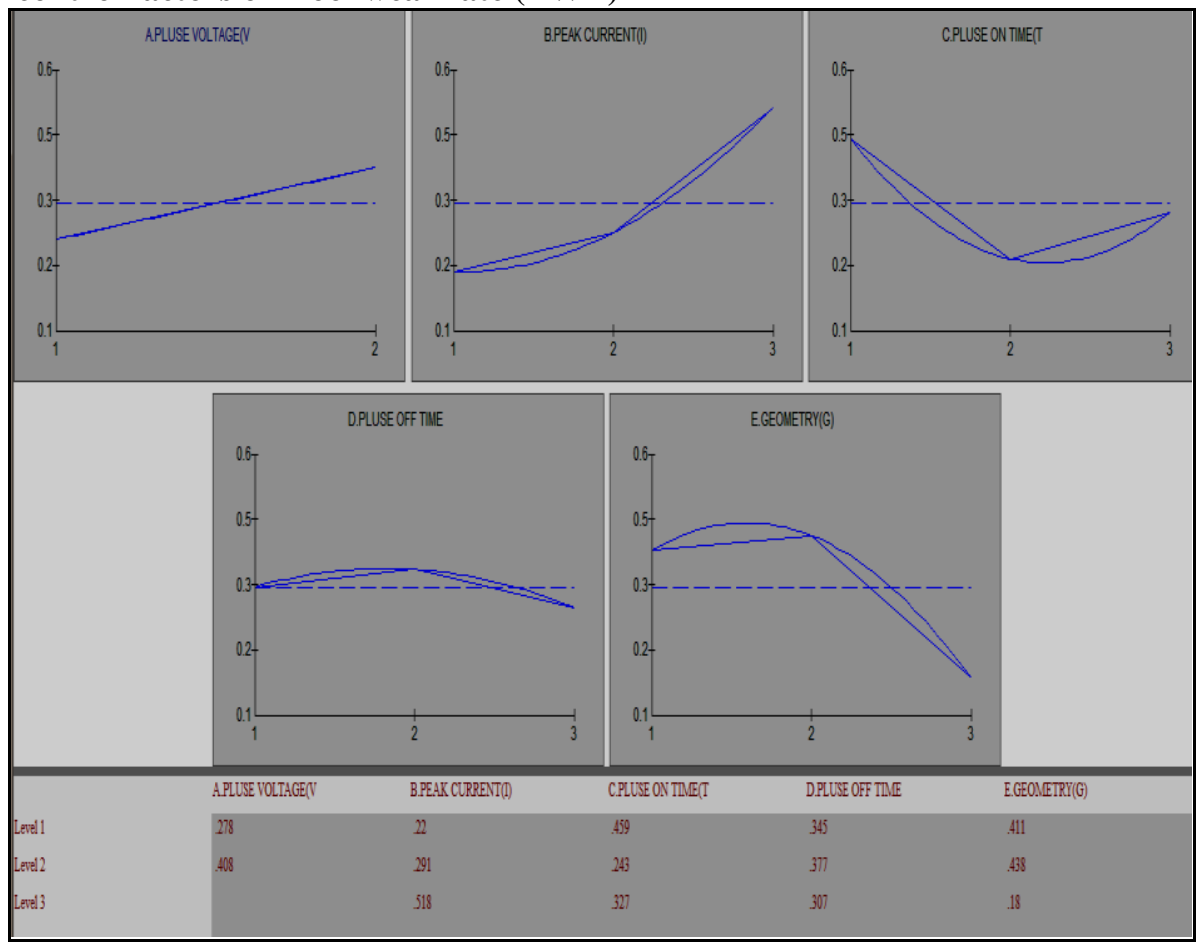

Fig 3. Effects of control factors on Tool wear rate

Fig 3. Graphically illustrates the effect of each level of five of the factors on the measured response in each plot $\mathrm{x}$-axis refers to the level , and $\mathrm{y}$-axis refer to the measured tool wear rate in $\mathrm{mm} 3 / \mathrm{min}$ in this peak current and pulse on time is the most significant factors influencing for tool wear the fig 6.6 shows that increasing in the discharge current from 6 to $10 \mathrm{~A}$ the tool wear rate is increasing., Because of peak current increases the pulse energy increases and thus more heat energy is produced in the tool work piece interface, leads to increase the melting and evaporation of the electrode. One can interpret that current has a significant direct impact on TWR and pulse on time is directly proportional to the tool wear rate.

\subsection{Effects of control factors on wear ratio (WR)}

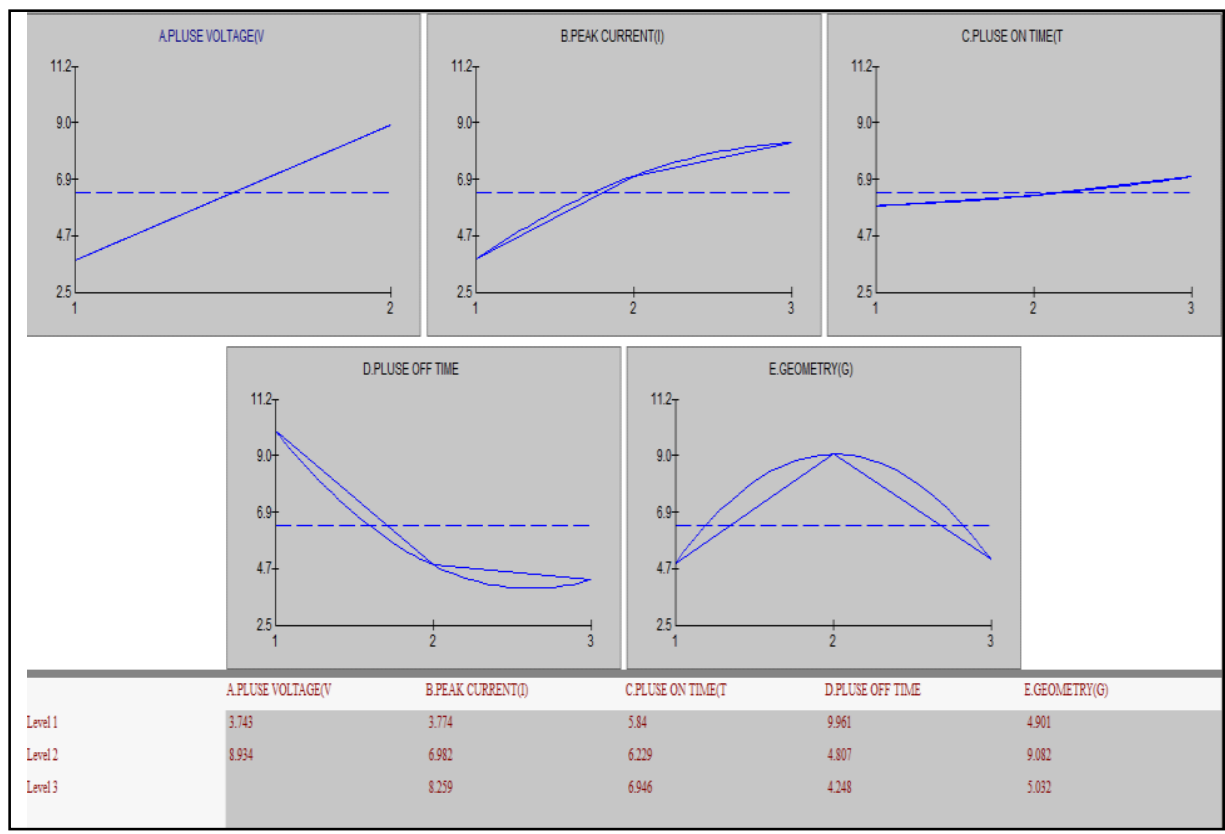

Fig 4. Effects of control factors on wear ratio

Fig 4. Graphically illustrates the effect of each level of five of the factors on the measured response in 
each plot, $\mathrm{x}$-axis refers to the level, and y-axis refer to the measured wear ratio in this peak voltage and pulse off time is the most significant factors influencing for tool wear ratio. The wear ratio is the ratio of TWR to MRR. It indicates the volume of tool material being lost while machining unit volume of the work piece the wear ratio overall increases with increase of current. Although MRR and TWR both increases with current but the amount of material eroded from the tool for unit volume of work piece being machined increases as a whole as current increases. However a reverse trend is seen with pulse off time. WR continuously decreases as observed. with the small increase of pulse on time WR increases.

\subsection{Analysis of variance (ANOVA) of MRR,TWR,ER}

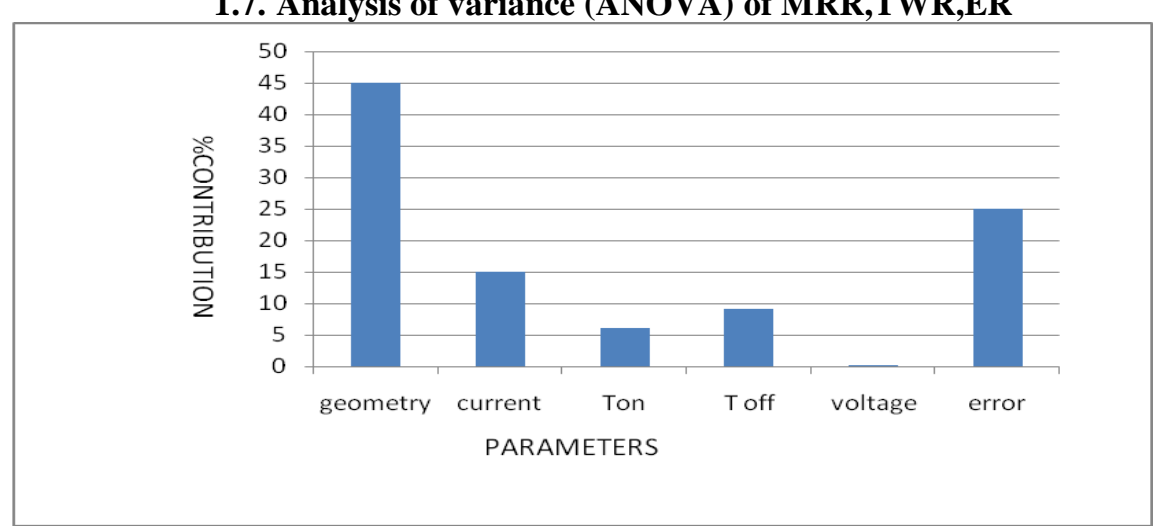

Fig 5. \% contribution Vs in put Parameter for MRR

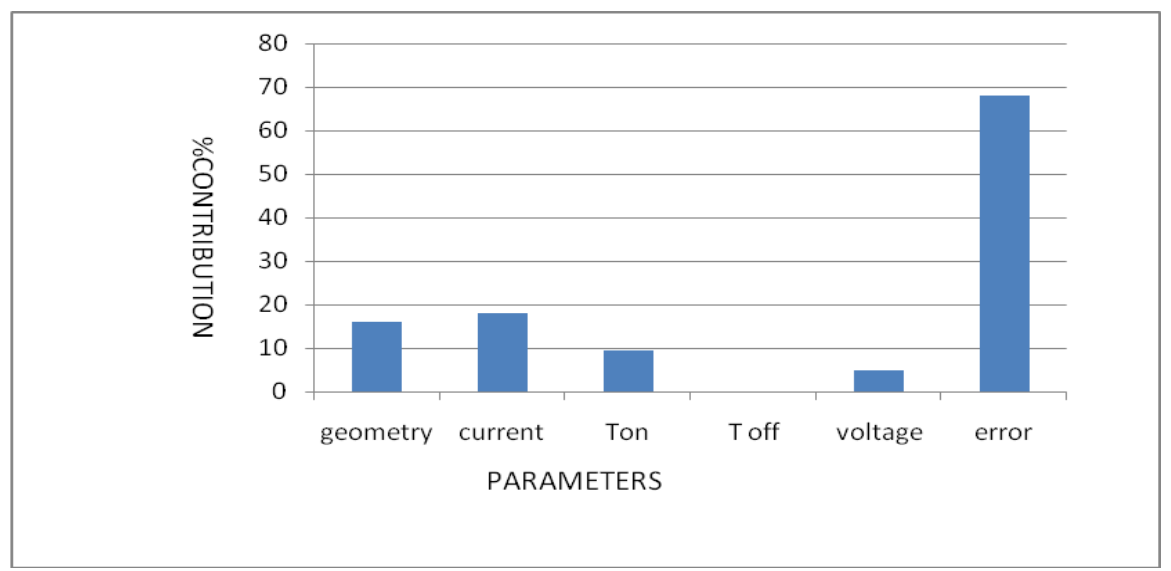

Fig 6.\% contribution vs. in put Parameter for TWR

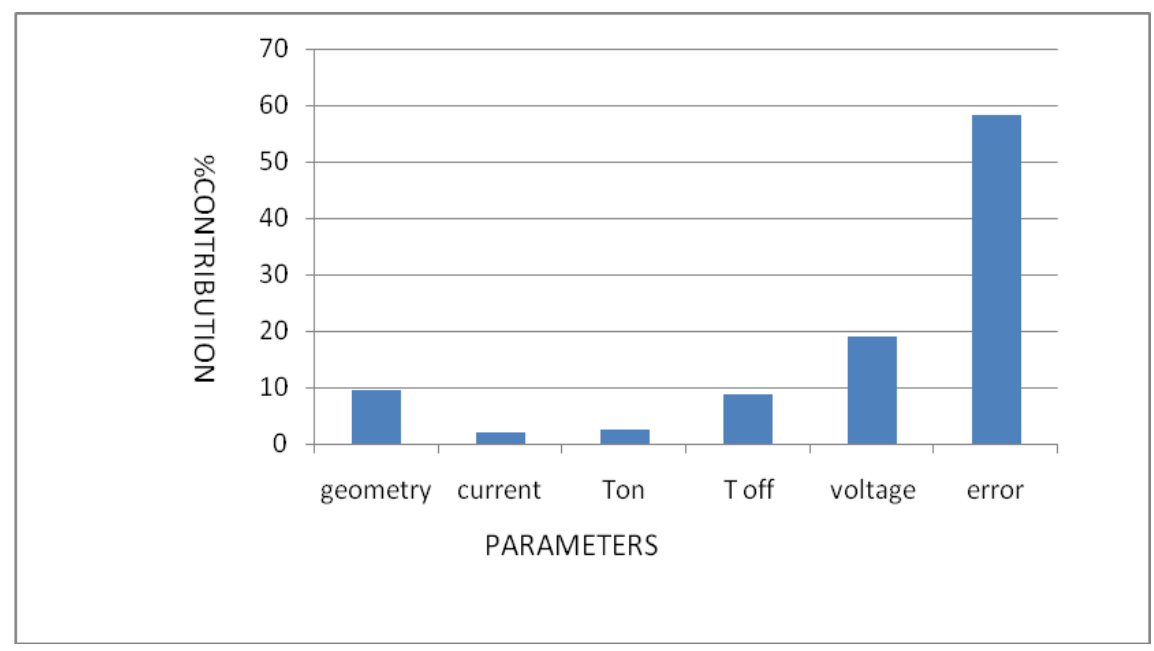

Fig 7. \% contributions vs. in put Parameter for WR 
The purpose of the analysis is to determine the factors and their interactions that have strong effects on the machining performance. It is evident from fig 5,6,7 that factors peak current , and tool geometry are the significant factors whereas factors pulse off time, voltage are the less significant factors for maximization of MRR .and current ,tool geometry ,pluse on time significant, and pulse pass time, voltage less significant factors for minimization of TWR . Similarly pulse voltage and pulse off time signifying factors for minimization of W.R

\subsection{Confirmation Experiment}

The optimal combination of machining parameters has been determined in the previous analysis however, the final step is to predict and verify the improvement of the observed values though the use of the optimal combination level of machining parameters the purpose of the confirmation experiment is to validate the conclusion drawn during the analysis phase the confirmation experiment is performed by conducting a test with specific combination of the factors and levels previously evaluated. In this study, a new experiment was designed with combination of factors.

- For MRR: Analysis of the results to the conclusion that factors at level peak voltage $-9 \mathrm{~V}$, Peak current 10Amp, pulse on time $50(\mu \mathrm{s})$, pulse off time $25(\mu \mathrm{s})$, Geometry $(\mathrm{E} 1)(\square)$ gives maximum MRR

- For TWR: Analysis of the results to the conclusion that factors at level peak voltage 8V, Peak current 6Amps, pulse on time $100(\mu \mathrm{s})$, pulse off time $50(\mu \mathrm{s})$, Geometry (E3) ('O) shape gives minimum TWR.

- For W.R: Analysis of the results lead to the conclusion that factors at level peak voltage $8 \mathrm{~V}$, Peak current 6 Amps, pulse on time $50(\mu \mathrm{s})$, pulse off time $5(\mu \mathrm{s})$, Geometry (E1) ( $\square$ ) shape gives minimum W.R

An experiment was conducted with new combination of factors and the results was noted down for each performance measure, an experiment result , an experiment was conducted for different factors combination and compared with estimated results .MRR,TWR,W.R were found to be $12.692 \mathrm{~mm} 3 / \mathrm{min}, 0.109 \mathrm{~mm} 3 / \mathrm{min}$ and .185 respectively, which fall within the $90 \%$ confidence interval of the predicted optimum parameters an error $1.20 \%$ for MRR,94.2\% for TWR ,87\% for W.R however ,the errors can be further reduced if the no. of measurements is increased .it shown that both MRR, and TWR and W.R improved by using the optimal setting of the process parameters determined by the Taguchi method .Based on Taguchi analysis, following results was obtained:

Table 5. Results of MRR, TWR and W.R.

\begin{tabular}{|c|c|c|c|}
\hline Condition & $\begin{array}{l}\text { Metal removal } \\
\text { rate( } \mathrm{mm} 3 / \mathrm{min})\end{array}$ & $\begin{array}{c}\text { Tool wear } \\
\text { rate(mm3/min) }\end{array}$ & Wear ratio $(\%)$ \\
\hline $\begin{array}{l}\text { Expected high values (at confidence } \\
\text { interval } 90 \% \text { ) }\end{array}$ & 14.826 & 0.116 & 5.16 \\
\hline Expected values using Taguchi & 12.692 & 0.109 & 0.21 \\
\hline $\begin{array}{l}\text { Experimental values at optimum } \\
\text { condition is }\end{array}$ & 12.451 & 0.103 & 0.18 \\
\hline
\end{tabular}

\section{Conclusion}

On the basis of the experimental results, the average of trial results, the analysis of ANOVA, and conformation test results, the following conclusions are drawn for the effective machining of EN-19 steel by the CNC sink type EDM process:

The recommended optimum condition for maximum MRR for EN19 Steel is as follows:

Pulse voltage-9V

Peak current -10amp

Pulse on time $-50(\mu \mathrm{s})$

Pulse off time $-25(\mu \mathrm{s})$

Tool geometry -G1 ( $\square$ ). Shape.

The recommended optimum condition for minimum tool wear rate for EN-19 steel is as follows:

Pulse voltage-8v

Peak current-6amp

Pulse on time $(\mu \mathrm{s})-100$

Pulse off time $(\mu \mathrm{s})-50$

Tool geometry- G3)('O) shape.

The recommended optimum condition for minimum wear ratio for EN-19Steel is as follows:

DOI: 10.9790/1684-1404012835 $\quad$ www.iosrjournals.org $\quad 34 \mid$ Page


Pulse voltage-8amp

Peak current-6amp

Pulse on time $-50(\mu \mathrm{s})$

Pulse off time $-50(\mu \mathrm{s})$

Tool geometry-G1 ( $\square$ ) Shape.

From the five process parameters studied it is found that tool geometry (45\%), and peak current $(15.3 \%)$ are the most significant parameter from Metal removal rate (MRR). Peak current (I) (18\%), Geometry $(16 \%)$ and pulse on time $(9.3 \%)$ are the most significant machining parameters, for the Tool wear rate (TWR).Voltage(19\%), and pulse off time (Toff)(8.71\%) are the influence parameters for the Wear ratio (W.R) MRR , TWR and WR were found $12.451 \mathrm{~mm} 3 / \mathrm{min}, 0.103 \mathrm{~mm} 3 / \mathrm{min}$ and $0.185 \%$ respectively After confirmation test, an error of $1.2 \%$ for the MRR and $5.8 \%$ for TWR and $13 \%$ for WR is observed.

\section{References}

[1]. Narcis Pellicer, Joaquim ,Ciurana and Jordi Delgado: Electrode geometry and process parameters influence on different feature geometry and surface quality in electrical discharge machining of AISI H13 steel J Intell Manuf DOI 10.1007/s10845-009-0320-8.

[2]. Mohd.amri lajis The implementation of taguchi method on EDM process of tungsten carbide, in this paper the cutting of tungsten carbide ceramic using EDM.faculty of mechanical and manufacturing,IIUM, Malaysia.

[3]. Sohani M.S. Gaitonde V.N. Siddeswarappa, B. And Deshpande, A.S., 2009.Investigations into the effect of tool shapes with size factor consideration in sink electrical discharge machining (EDM) process. International Journal of Advanced Manufacturing Technology, 1-15Int J Adv Manuf Technol (2010) 47:395-402 DOI 10.1007/s00170-009-2208-3

[4]. Lin, y- Cheng, C.-. Su, B. Hwang, L.-2006. Machining characteristics and Optimization of machining parameters of SKH 57 highspeed steel using electrical-discharge machining based on Taguchi method. Materials and Manufacturing Processes, 21(8), 922-929.

[5]. H.S Payal, Rajesh Choudhary and Sarabjeet Singh. Analysis of electro discharged machined surface of EN31 tool steel. Journal of Scientific and Industrial Research, Vol. 67, December 2008, pp. 1072-1077

[6]. Khanra, A. K., Sarkar, B. R., Bhattacharya, B., Pathak, L. C., \& Godkhindi,M. M. (2007). Performance of ZrB2-Cu composites an EDM electrode. Journal of Materials Processing Technology,183, 122-126.

[7]. Fenggou, C., \& Dayong, Y. (2004). The study of high efficiency and intelligent optimization system in EDM sinking process. Journal of Materials Processing Technology, 149(1), 83-87. doi:10.1016/ j.jmatprotec.2003.10.059

[8]. M.R. Shabgard, B. Sadizadeh and H. Kakoulvand.The Effect of Ultrasonic Vibration of Workpiece in Electrical Discharge Machining of AISIH13 Tool Steel.World Academy of Science, Engineering and Technology 522009.

[9]. B. H. Yan, C. C. Wang, W. D. Liu and F. Y. Huang Department of Mechanical Engineering, National Central University, ChungLi, Taiwan Int J Adv Manuf Technol (2000) 16:322-333 2000 Springer-Verlag London Limited

[10]. García Navas,V., Ferreres, I.,Marañón, J. A.Garcia-Rosales, C.,\&Gil Sevillano, J. (2008). Electro-discharge machining (EDM) versus hard turning and grinding-comparison of residual stresses and surface integrity generated in AISI O1 tool steel. [14]. Journal Materials Processing Technology, 195(1-3), 186-194.

[11]. Groover, M. P. (1996). Fundamentals of modern manufacturing. NJ:Prentice-Hall Int J Adv Manuf Technol (2010) 47:395-402 DOI 10.1007/s00170-009-2208-3

[12]. Ho, K. H., \& Newman, S. T. (2003). State of the art electrical discharge machining (EDM). International Journal of Machine Tools and Manufacture, 43(12-13), 1287-1300. 